\title{
MPs are to investigate need for drug companies to share clinical trial data
}

\author{
Gareth lacobucci
}

BMJ

MPs are set to investigate drug companies' sharing of clinical trial data, after mounting pressure on the issue, the chairman of the health select committee has announced.

In a discussion panel at the NHS Alliance's conference in Bournemouth today, the committee's chairman, Stephen Dorrell, confirmed that MPs would examine the issue as a matter of priority within the next 12 months.

The announcement came after the $B M J$ recently launched its open data campaign, which aims to achieve "appropriate and necessary independent scrutiny of data from clinical trials" and to "highlight the problems caused by lack of access to data."1

In September this year the doctor and science writer Ben Goldacre published Bad Pharma, a book taking the drug industry to task over the issue, in which he claimed that the failure to disclose data was misleading doctors and harming patients.

Sarah Wollaston, the MP for Totnes, a member of the Health Committee, and a former GP, who also appeared on the panel, said that it was important to tackle the issue now while the European regulations were under review.

She said, "Patient safety is put at risk by inappropriate prescribing and when doctors do not know the full clinical data. The European regulations are under review, so there are certain aspects of this which are time critical if we are going to able to feed into that."

Wollaston, who has lobbied the committee on the problems, said that she had met Goldacre and had concluded that it was "absolutely right that politicians take this forward."

She said, "For far too long now we have allowed the government to buy drugs at vast expense. If we take [the example of] Tamiflu, we spent $£ 500 \mathrm{~m}-£ 1$ in every $£ 200$ that was spent in the NHS in 2009-without actually knowing all of the clinical trial data. I think that's totally unacceptable. We've seen it happen with so many other drugs in the past. Would you buy a car without knowing how many miles to the gallon it does and what the safety data were?"

She added, "I feel the NHS should be far more muscular and have many levers to actually insist on seeing all the data, [and] that we see proper professional accountability and also professional practice around it. Why should doctors be forced to sign gagging clauses when they undertake medical research?

"I think we need a root and branch review of the way the pharmaceutical industry operates. There are many wonderful things about the drugs we have, but we have to know all the safety data."

Dorrell said that the issue was "pretty close to the top of the list of subjects" that the committee would be examining but added that he needed to "secure consensus from 11 strong minded people" [on the committee] before announcing further details. He said, "Sarah has been a very effective advocate of what has been described in another context as the duty of candour. That seems to be a principle that we definitely need to carry forward." He pointed out that the government's own ongoing review of the Pharmaceutical Price Regulation Scheme and of value based pricing of drugs made the issue time sensitive.

"It's not going to be an issue that we shall get through next year without needing to address," he declared.

For more on the $B M S$ s open data campaign go to bmj.com/tamiflu.

1 Godlee F. Clinical trial data for all drugs in current use. BMJ 2012;345:e7304. 